\section{The Effect of Students Perceptions on The Use of Jigsaw Learning Methods on Student Learning Outcomes in Class X IPS Budhi Warman II East Jakarta}

\author{
Pengaruh Persepsi Siswa pada Penggunaan Metode Pembelajaran Jigsaw pada Mata \\ Pelajaran Ekonomi terhadap Hasil Belajar Siswa Kelas X IPS SMA Budhi Warman II \\ Jakarta Timur
}

\author{
Yosiana Rut Suryaningsih \\ Universitas Indraprasta PGRI \\ Jl. Raya Tengah No.80, RT.6/RW.1, Gedong, Kec. Ps. Rebo, Kota Jakarta Timur, Daerah \\ Khusus Ibukota Jakarta 13760
}

Vol. 1, No. 1,

October 2019,

pp. 6-9

e-ISSN:

2686-5009

\begin{abstract}
This study aims to knows influence the perceptions of students on the use of jigsaw learning methods in Economic Subjects on the learning outcomes of Class X IPS students at Budhi Warman II High School in East Jakarta. The method used in this research is quantitative. The population in this study were students of class X IPS 1 and X IPS 3 at Budhi Warman II Senior High School. So that out of 115 IPS class X students, the researchers took a population of 75 students to be sampled from two classes. In the experimental class which numbered 40 students will be given material with a jigsaw learning model while the control class numbering 35 students will be given material with a conventional learning model. Data collection techniques by conducting field research are observation, tests containing questions or exercises or other tools used to measure skills, measurements, intelligence, abilities or talents possessed by individuals or groups, and library research, as well as documentation. The research instrument used was a multiple choice test consisting of 8 questions. Data analysis techniques used descriptive data analysis, including the mean, median mode, variance, and standard deviation and hypothesis testing. The results in this study indicate that there is an effect of the use of Jigsaw Learning Methods on Student Learning Outcomes in Economic Subjects in X grade IPS students and from the results of students' perceptions on the perception statement sheet of students in class X IPS expressing liking the jigsaw learning method in economic subjects at Budhi High School Warman II, East Jakarta 2019/2020 Academic Year.
\end{abstract}

Keywords: perceptions of students, jigsaw learning methods

\title{
PENDAHULUAN
}

Dalam penyampaian materi biasanya guru menggunakan metode ceramah, di mana seluruh informasi dari guru, dan siswa hanya mendengar dan mencatat, hal ini sedikit memberi peluang bagi para siswa untuk bertanya. Dengan demikian suasana pembelajaran hanya bersifat satu arah, siswa menjadi pasif dan berpengaruh terhadap kreativitas siswa. Upaya peningkatan kreativitas dan prestasi siswa tidak lepas dari metode, teknik pembelajaran dan faktor tenaga kependidikan. Metode dan teknik pembelajaran sangat beragam, penerapan dan pelaksanaannya di kelas saat berinteraksi langsung dengan peserta didik, tergantung dari kecakapan dan kreativitas guru. Guru yang kreatif dituntut untuk mengembangkan berbagai macam metode dan teknik pembelajaran di antaranya metode pembelajaran kooperatif dengan teknik jigsaw. 
Literatus is a journal published by PT Traindo Bangun Negeri, issued two times in one year. Literatus is a scientific publication media in the form of conceptual paper and field research related to general thinking paradigm. It is hoped that Literatus can become a media for academics and researchers to publish their scientific work and become a reference source for the development of science and knowledge.

Our focus:

Social and Culture

Our Scope:

Humanities,

Education,

Management,

History,

Economics,

Linguistics,

Literature,

Religion,

Politics,

Sociology,

Anthropology, and others.

Metode pembelajaran kooperatif dengan teknik jigsaw, mudah diterapkan di dalam kelas, dan menjadi lebih menarik untuk dikaji, sebab siswa-siswi akan lebih kreatif. Pembelajaran kooperatif model jigsaw ini juga mengambil pola cara bekerja sebuah gergaji (jigsaw), yaitu siswa melakukan sesuatu kegiatan belajar dengan cara bekerja sama dengan siswa lain untuk mencapai tujuan bersama.

Metode kooperatif dengan teknik jigsaw, mempunyai peran yang sangat penting dalam proses pembelajaran yang berdampak terhadap hasil belajar siswa. Hasil belajar menjadi perhatian utama bagi guru dalam menjalankan tugasnya. Kemampuan mengajar guru yang tinggi merupakan tuntutan yang benar-benar harus dipenuhi, agar mutu pendidikan lebih meningkat. Sehingga dapat mewujudkan generasi muda penerus masa depan yang unggul dan mandiri. Oleh karena itu metode dan teknik mengajar serta hasil belajar siswa perlu ditingkatkan terus.

Berdasarkan uraian di atas maka penulis tertarik untuk meneliti Pengaruh Persepsi Siswa pada Penggunaan Metode Pembelajaran Jigsaw pada Mata Pelajaran Ekonomi Terhadap Hasil Belajar Siswa Kelas X IPS SMA Budhi Warman II Jakarta Timur.

\section{Hasil Belajar}

"Hasil belajar siswa menurut Benjamin S. Bloom pada umumnya adalah menyangkut perubahan tiga ranah yakni ranah kognitif, afektif, dan ranah psikomotorik" (Nana, 2005). Menurut Abdurrahman (Asep \& Abdul, 2008) "hasil belajar adalah kemampuan yang diperoleh anak setelah melalui kegiatan belajar. Siswa dikatakan berhasil dalam belajar ketika siswa dapat mencapai tujuan-tujuan pembelajaran atau tujuan instruksional."

Hasil belajar dapat digunakan oleh guru untuk dijadikan ukuran atau kriteria dalam mencapai suatu tujuan pendidikan. Sedangkan di dalam dunia pendidikan hasil belajar digunakan sebagai alat evaluasi guru, di antaranya berupa tanya jawab secara lisan kepada siswa mengenai materi yang telah dijelaskan ataupun berupa soal tertulis yaitu pilihan ganda atau essay.

\section{Persepsi}

Persepsi secara etimologi atau harfiyah mempunyai arti tanggapan penerimaan langsung dari sesuatu, proses seseorang mengetahui beberapa pancainderanya. Secara definisi, persepsi adalah mengenal sesuatu alat indera. Anak didik akan memperoleh pengertian dan pemahaman tentang dunia dan sekitarnya dengan jelas.

Slameto (2003: 104) menyimpulkan terdapat "beberapa hal yang mempengaruhi kejelasan dalam persepsi misalnya keadaan alat indera (mata, telinga, dan sebagainya), perhatian dan minat, pengalaman serta kejelasan obyek yang dikenalnya".

\section{Metode pembelajaran jigsaw}

Metode jigsaw didesain untuk meningkatkan rasa tanggung jawab siswa terhadap pembelajarannya sendiri dan juga pembelajaran orang lain. Siswa tidak hanya mempelajari materi yang diberikan, tetapi mereka juga harus siap memberikan dan menjabarkan materinya tersebut kepada anggota kelompoknya yang lain.

Pada metode pembelajaran kooperatif tipe jigsaw, terdapat kelompok asal dan kelompok ahli. Kelompok asal yaitu kelompok induk siswa yang beranggotakan siswa dengan kemampuan, asal, dan latar belakang keluarga yang beragam. Kelompok asal merupakan gabungan dari beberapa ahli. Kelompok ahli yaitu kelompok siswa yang terdiri dari anggota kelompok asal yang berbeda yang ditugaskan untuk mempelajari dan mendalami topik tertentu dan menyelesaikan tugas-tugas yang berhubungan dengan topiknya untuk kemudian dijelaskan kepada anggota kelompok asal. 


\section{METODE}

Metode penelitian yang digunakan dalam penelitian ini adalah metode kuantitatif. Populasi dalam penelitian ini adalah peserta didik kelas X IPS 1 dan X IPS 3 SMA Budhi Warman II. Sehingga dari 115 peserta didik kelas X IPS, peneliti mengambil populasi sebanyak 75 peserta didik untuk dijadikan sampel dari dua kelas. Pada kelas eksperimen yang berjumlah 40 peserta didik akan diberi materi dengan model pembelajaran jigsaw sedangkan kelas kontrol berjumlah 35 peserta didik diberi materi dengan model pembelajaran konvensional. Teknik pengumpulan data dengan melakukan penelitian lapangan yaitu observasi, tes yang berisi pertanyaan atau latihan atau alat lain yang digunakan untuk mengukur keterampilan, pengukuran, inteligensi, kemampuan atau bakat yang dimiliki oleh individu atau kelompok, dan penelitian kepustakaan, serta dokumentasi. Instrumen penelitian yang digunakan adalah tes yang berbentuk pilihan ganda terdiri dari 8 soal. Teknik analisis data menggunakan analisis data dekriptif yaitu antara lain mean, median modus, varian, dan simpangan baku serta uji hipotesis. Pengujian hipotesis menggunakan hipotesis statistik.

\section{HASIL DAN PEMBAHASAN}

\section{Hasil}

Dari perhitungan hasil belajar kelas Kontrol (X IPS 1) di atas maka, terdapat rentangan kelas dari nilai tertinggi dikurang nilai terendah sebesar 30, jumlah kelas 6,095 dibulatkan menjadi 6 kelas, panjang kelas 5 dibulatkan menjadi 5 kelas didapat mean 75; median 76,85; modus 75, 33; simpangan baku 41,17; dan varians 6,416 .

Dari perhitungan hasil belajar kelas Eksperimen (X IPS 3) di atas maka, terdapat rentangan kelas dari nilai tertinggi dikurang nilai terendah sebesar 35, jumlah kelas 6,286 dibulatkan menjadi 6 kelas, panjang kelas 5,83 dibulatkan menjadi 6 kelas didapat mean 372,07; median 120,75; modus 87,75; simpangan baku 141,67; dan varians 11,902 .

Maka terjadi perbandingan yang cukup signifikan terhadap hasil belajar kelas Kontrol (X IPS 1) dan hasil belajar kelas Eksperimen (X IPS 3). Dari 35 peserta didik kelas Kontrol dan dari 40 peserta didik kelas Eksperimen diperoleh nilai rata-rata, median, dan modus lebih tinggi pada hasil belajar kelas Eksperimen (X IPS 3) yaitu setelah penggunaan metode pembelajaran Jigsaw dari pada hasil belajar kelas Kontrol (X IPS 1) dengan menggunakan metode pembelajaran konvensional.

Hasil pengujian hipotesis Kriteria $t_{\text {hitung }}>t_{\text {tabel }}(97,4>1,725)$ maka $\mathrm{H}_{0}$ ditolak dan $\mathrm{H}_{1}$ diterima pada $\alpha=0,05$. Dengan demikian dapat diartikan bahwa terdapat pengaruh yang signifikan setelah penggunaan "metode pembelajaran kooperatif tipe jigsaw pada mata pelajaran ekonomi di kelas X SMA Budhi Warman II" sebagai kelompok kelas Eksperimen (X IPS 3).

\section{Pembahasan}

Berdasarkan hasil penelitian yang telah dilakukan, terdapat pengolahan hasil belajar ekonomi kelas X IPS yaitu terdapat rentangan kelas Kontrol 30 sedangkan kelas Eksperimen 35; jumlah kelas kelas Kontrol 6,095 dibulatkan (6) sedangkan kelas Eksperimen 6,286 dibulatkan (6); panjang kelas kelas Kontrol 5 dibulatkan (5) sedangkan kelas Eksperimen 5,83 dibulatkan (6); didapat mean kelas Kontrol 75 sedangkan kelas Eksperimen 372,07; median kelas Kontrol 76,85 sedangkan kelas Eksperimen 120,75; modus kelas Kontrol 75,33 sedangkan kelas Eksperimen 87,75; simpangan baku kelas Kontrol 41,17 sedangkan kelas Eksperimen 141,67; dan varians kelas Kontrol 6,416 sedangkan kelas Eksperimen 11,902. Maka terjadi perbandingan yang cukup signifikan terhadap hasil belajar kelas 
Literatus is a journal published by PT Traindo Bangun Negeri, issued two times in one year. Literatus is a scientific publication media in the form of conceptual paper and field research related to general thinking paradigm. It is hoped that Literatus can become a media for academics and researchers to publish their scientific work and become a reference source for the development of science and knowledge.

Our focus:

Social and Culture

Our Scope:

Humanities,

Education,

Management,

History,

Economics,

Linguistics,

Literature,

Religion,

Politics,

Sociology,

Anthropology,

and others.

Kontrol dan hasil belajar kelas Eksperimen. Dari 40 peserta didik kelas eksperimen dan dari 35 peserta didik kelas Kontrol diperoleh nilai rata-rata, median, dan modus lebih tinggi pada hasil belajar kelas Eksperimen yaitu setelah penggunaan metode pembelajaran jigsaw dari pada hasil belajar kelas Kontrol.

Berdasarkan persyaratan analisis, maka sebelum dilakukan pengujian hipotesis perlu dilakukan pengujian terlebih dahulu terhadap data hasil penelitian. Setelah dilakukan uji persyaratan analisis data, diperoleh bahwa kelas Kontrol dan kelas Eksperimen berdistribusi normal dan homogen. Selanjutnya dilakukan diuji hipotesis penelitian menggunakan uji-t dengan kriteria pengujian hipotesis didasarkan pada taraf signifikansi $\alpha=0,05 \mathrm{dan} \mathrm{dk} n-2$ dengan kesimpulan sebagai berikut : pengujian dengan Kriteria $t_{\text {hitung }}>t_{\text {tabel }}(97,4>1,725)$ maka $\mathrm{H}_{0}$ ditolak dan $\mathrm{H}_{1}$ diterima diketahui bahwa terdapat pengaruh yang signifikan terhadap hasil belajar ekonomi setelah penggunaan metode kooperatif tipe jigsaw di kelas X SMA Budhi Warman II Jakarta Timur.

Hasil yang didapat akan memperkuat teori dan hasil penelitian-penelitian terdahulu, bahwa metode pembelajaran jigsaw dapat meningkatkan hasil belajar ekonomi.

Penelitian Sudharmini, Lasmawan, \& Natajaya, (2014) juga mendukung temuan ini yang menunjukkan bahwa ternyata skor rata-rata hasil belajar IPS siswa yang mengikuti pembelajaran dengan model pembelajaran kooperatif tipe jigsaw lebih tinggi daripada sikap siswa yang mengikuti pembelajaran dengan pembelajaran konvensional pada siswa kelas $\mathrm{V}$ Sekolah Dasar Gugus IV Jimbaran, Kuta Selatan. Dengan demikian, dapat disimpulkan hasil belajar IPS siswa yang mengikuti pembelajaran dengan model pembelajaran kooperatif tipe jigsaw lebih tinggi daripada sikap siswa yang mengikuti pembelajaran dengan pembelajaran konvensional pada siswa kelas V Sekolah Dasar Gugus IV Jimbaran, Kuta Selatan.

\section{PENUTUP}

Penelitian ini menguji Pengaruh Persepsi Siswa Pada Penggunaan Metode Pembelajaran Jigsaw Pada Mata Pelajaran Ekonomi Terhadap Hasil Belajar Siswa (Studi Eksperimen pada Peserta Didik Kelas X IPS SMA Budhi Warman II, Jakarta Timur Tahun Pelajaran (2019/2020). Berdasarkan hasil penelitian dan pembahasan yang diuraikan sebelumnya, dari analisis serta perhitungan data yang telah dilakukan, dapat disimpulkan bahwa terdapat Pengaruh Penggunaan Metode Pembelajaran Jigsaw terhadap Hasil Belajar Siswa Pada Mata Pelajaran Ekonomi peserta didik kelas X IPS dan dari hasil persepsi siswa pada lembar pernyataan persepsi para siswa kelas X IPS menyatakan menyukai metode pembelajaran jigsaw pada mata pelajaran ekonomi di SMA Budhi Warman II, Jakarta Timur Tahun Pelajaran 2019/2020.

\section{DAFTAR PUSTAKA}

Asep, J., \& Abdul, H. (2008). Evaluasi Pembelajaran. Jakarta: Multi Press.

Nana, S. (2005). Penilaian Hasil Proses Belajar Mengajar. Bandung: PT Remaja Rosdakarya. Slameto. (2003). Belajar dan Faktor-Faktor yang Mempengaruhi. Jakarta: Rineka Cipta.

Sudharmini, L. S., Lasmawan, I. W., \& Natajaya, I. N. (2014). Pengaruh Model Pembelajaran Kooperatif Tipe Jigsaw terhadap Motivasi Belajar dan Hasil Belajar IPS Siswa Kelas V Sekolah Dasar Gugus IV Jimbaran, Kuta Selatan. E-Journal Program Pascasarjana Universitas Pendidikan Ganesha Program Studi Pendidikan Dasar, 4, 1-10. 